\title{
O comportamento sexual de homens de baixa renda com disfunção erétil
}

Laura Meyer da Silva ${ }^{1}$

\begin{abstract}
The sexual Behavior of Law Income men with Erectile malfunction.

The aim of this was to design the profile of the low income patient with Erectile malfunction tha comes to Santa Casa de Misercórdia (charity Hospital).

The Patients who took part in this research were outpatient sent from the Department of Andrology to the Department os Psychology of Santa Casa de Misericórdia of Porto Alegre.

One hundred patients were interviewed and, in according with literature, it was observed the profile of low income patient does not entirely differ from that of other social classes. However, it bears ots ows peculiarites.
\end{abstract}

1 Psicóloga Clínica, coordenadora do Departamento de Psicologia Clínica da Santa Casa de Misericórdia de Porto Alegre. 
We felt the need to approach the patient in order to better understand him, thus providing adequate treatment as well as preventive care. Professionals of parallel areas might also profit from the information of this paper.

\section{RESUMO}

O objetivo desta pesquisa foi o de elaborar um perfil do comportamento sexual de homens de baixa renda com disfunção erétil.

Os pacientes que participaram deste trabalho eram encaminhados pelo Ambulatório de Andrologia da Santa Casa de Misericórdia de Porto Alegre para o Setor de Psicologia Clínica da mesma Instituição.

Cem pacientes foram entrevistados e, de acordo com a literatura, foi observado que não existem diferenças entre eles e outras classes sociais. Entretanto encontrou-se características peculiares desta amostra.

\section{INTRODUÇÃO}

Esta pesquisa tem como objetivo conhecer o paciente com disfunção erétil, proveniente da classe social de baixa renda, caracterizandoo quanto à idade, à freqüência da prática do coito e suas dificuldades na hora da relação sexual e demais fatores que estão relacionados com a disfunção, tais como: problemas de saúde, familiares, fantasias, desejos etc...

Os dados foram alcançados através de escolhe aleatória de entrevistas realizadas de cem (100) pacientes de classe baixa que são encaminhados pelo ambulatório de Andrologia da Santa Casa de Misericórdia de Porto Alegre, com queixa de disfunção erétil, para o ambulatório de Psicologia da mesma Instituição.

A experiência clínica que formou o processo terapêutico iniciado pelas dificuldades relativas ao tratamento de problemas sexuais de clínica procedentes deste ambulatório, permitiu que as entrevistas com os pacientes resultassem nesta pesquisa sobre a disfunção erétil que, dentre as disfunções sexuais, é a que provoca maior número de complicações para o homem na sua sexualidade.

As limitações conseqüentes acabam causando perturbações em todas as áreas de sua vida. O homem ao se reprimir, limitando sua sexualidade, distorce a realidade, deixando-se levar então por atitudes, fantasias, e sentimentos negativos, podendo levá-lo ao desequilíbrio interior afetando sua saúde mental, física e emocional. 
Neste sentido, é essencial engajar-se na luta por uma sexualidade melhor, de tal modo que desistir disso é desistir de ser pessoa. A potência do homem e o orgasmo da mulher passam a ser mais que direitos: são deveres. A terapia do sexo, de uma ou de outra forma, está sendo empregada nas desordens sexuais, pois se preocupa principalmente com o aperfeiçoamento das funções sexuais.

\section{A DISFUNÇÃO ERÉTIL}

O potencial para o prazer erótico parece começar com o nascimento e não deve extinguir-se até a morte. Entretanto, a idade ajusta, de maneira significativa, o componente biológica da nossa sexualidade, de forma que a intensidade e a qualidade da resposta sexual variam consideravelmente nas diferentes idades.

Os dados de Kinsey indicam e os estudos de Masters e Johnson confirmam que os homens experimentam o pico da capacidade e responsividade sexuais ao redor dos 17 e 18 anos e, daí em diante, demonstram um declínio constante. Os componentes da resposta sexual são diretamente afetados pela idade.

Para o homem, a dificuldade erétil é quase sempre de ordem psicológica, entretanto causas mais profundas e mais remotas, como conflito inconsciente ou desarmonia conjugal, podem freqüentemente ser a base das transações tensas que causaram o problema sexual específica e continuar a evocar a ansiedade quando os pacientes tentarem fazer amor.

A disfunção Erétil ou Impotência é a dificuldade do homem ficar com o pênis ereto.

Esta dificuldade pode ser ocasionada por problemas orgânicos e/ou psicológicos. Pode ser primária, quando o homem nunca funcionou, bem, ou secundária, que é a mais comum. A secundária é quando funcionava bem, mas passa a ter dificuldades depois.

Kaplan $(1977,0.249)$ diz que a taxa de incidência da disfunção erétil não parece ser afetada por fatores raciais ou sócio-econômicos, " $A$ procura da terapia sexual é tão premente no gueto como na Park Avenue.

Conforme Wincze e Carey (1991, p. 28), citando a última edição do DSM III R, os critérios para o diagnóstico das disfunções eréteis masculinas (302.72) são: A. ou (1) ou (2):

A.

1) Fracasso persistente ou recorrente, parcial ou completo do homem, em atingir ou manter ereção até a conclusão da Atividade Sexual. 
2) Falha da sensação subjetiva, persistente ou recorrente, de excitação sexual e de prazer no homem durante a Atividade Sexual.

B. Ocorrência não exclusivamente durante a evolução de um outro Distúrbio do Eixo 1(outro que não uma Disfunção Sexual). como Depressão Maior.

Para Masters e Johnson (1985, p. 100) o homem com disfunção erétil primária nunca é capaz de obter e/ou manter uma ereção com qualidade suficiente para alcançar a união coital bem sucedida. Se a ereção se estabelece e então é perdida sob distrações reais ou imaginatórias relacionadas com o ato sexual, a ereção geralmente se dissipa antes da resposta ejaculatória.

"Nenhum homem é considerado impotente primária se obteve sucesso em qualquer tentativa de introdução, tanto em relacionamento heterossexual como homossexual”. (Masters Johnson, 1985, p. 100).

Ainda citando Masters e Johnson (1985, p. 114), padrão comum de impotência secundária é o sucesso na primeira relação sexual e performance efetiva que continue nos primeiros cinquenta, cem ou mesmo mil ou mais encontros sexuais, até se registrar um episódio fracassado na união coital.

O primeiro fracasso pode se tornar precursos, e conforme a apreensão cresce durante os epidódios de ereção, um forte padrão de falha eretiva pode estabelecer-se subseqüentemente.

"Quando a média de fracassos na união coital bem sucedida se aproxima de $25 \%$ das oportunidades, deve-se aceitar o diagnóstico clínico de impotência secundária” (Masters e Johnson, 1985. p. 115).

Kaplan (1977, p. 250) diz que em geral o prognóstico, tanto para o tratamento como para remissão espontânea, está diretamente relacionado com a duração do sintoma. Ainda, quanto ao prognóstico: é melhor para a impotência secundária pois esta é propensa a associar-se a sérios distúrbios psiquiátricos subjacentes ou endócrinos.

"A impotência pode ser devida a fatores, físicos ou psicológicos. A impotência psicogênica pode estar associada à perda geral da libido e a dificuldade ejaculatória, mas a patologia essencial é a falha do reflexo erétil. Especificamente o mecanismo do reflexo vascular deixa de bombear sangue suficiente nos corpos cavernosos do pênis para torná-lo firme e ereto. O homem impotente, embora capaz de sentir-se estimulado e excitado numa situação sexual e queira fazer amor não fica com o pênis ereto. Os reflexos eréteis 
e ejaculatório são dissociáveis e alguns homens são capazes de ejacular apesar de seu pênis flácido. “ Kaplan (1977, p. 129).

Para Masters e Johnson (1982, p. 50), aproximadamente 10 à 15\% dos homens com impotência parecem ter base primordialmente orgânica enquanto que 85 à $90 \%$ parecem ter origem primariamente psicogênica.

Suplicy (1987, p. 239), analisando as causas da dificuldade de ereção, cita em seu livro "Conversando sobre Sexo", que os estudos acreditam que $90 \%$ dos casos de Disfunção Erétil são de ordem psicológica. Diz ainda que a origem pode ser por conflitos intra-psíquicos inconscientes, como ter vontade de sentir prazer erótico e ter medo da punição, medo de castração se tiver relação, até algo situacional como, por exemplo, tabus sexuais ou medo de fracassar.

Alguns pacientes alegam que só vêm buscar ajuda porque tem medo de que suas mulheres procurem outros homens para se realizarem.

Kusnetzoff (1978, p. 27) diz que: "O distúrbio sexual embora esteja alojado em um dos membros do casal, no homem, este caso, nunca é apenas desse membro. O problema sexual é sempre de ambos”.

Para Masters e Johnson (1988, p. 214). 'o conceito cultural de que o homem deve aceitar total responsabilidade no estabelecimento da união sexual bem sucedida colocou sobre cada homem o peso psicológico do processo de coito e aliviou as mulheres de qualquer sugestão de responsabilidade similar no seu sucesso.'

Falando sobre o papel da mulher, Masters e Johnson (1988. O. 214) ressaltam:

"A mulher precisa estar apenas fisicamente disponivel para a união coital ou mesmo para propagar a raça (...) Durante o coito, a mulher tem apenas que permanecer deitada para ser fisicamente potente. Enquanto esse papel de total passividade não é mais uma abordagem psicológica aceitável, em vista da qual necessidade de participação feminina ativa, é ainda um fato psicológico irrevogável que a mulher precise ficar deitada para ser potente".

Masters e Johnson (1988, 0.215), analisando a questão da dupla moral, salientam que esta leva o homem a assumir a responsabilidade de ser especialista em sexo. Que seja o responsável e controle a situação a que leve a perceira ao orgasmo. Enquanto esta assume uma posição onde não possue sentimentos sexuais (pois é "direita") o homem fzz sexo na mulher para suas satisfação, não encorajando a troca entre o casal.

A dupla moral e suas variações podem criar vários problemas sexuais, A mulher por exemplo, pode desenvolver uma concepção, estre- 
ita da integração sexual. Achando que deve impelir o homem de conseguir tudo o que quer", seu potencial de prazer diminui devido à suas necessidade de estabelecer limites. O homem, por outro lado, pode sentir-se compelido a provar sua masculinidade fazendo avanços sexuais mesmo quando não está especialmente com vontade nem sente atração por sua companheira”. (Masters e Johnson, 1988, p. 215).

Os mesmos autores colocam que existe ainda a crença de que o homem tem mais interesse por sexo que a mulher e que assume um papel ativo, enquanto as mulheres são passives.

Também que a exitação sexual masculina ocorre rápida e automaticamentem, enquanto as mulheres necessitam de mais tempo, palavras dores e tratamento especial e que mesmo asaim têm dificuldade de se excitar.

Masters e Johnson (1988, p. 216) afirmam queL "Em geral os homens tentam atender às expectativas culturais e as mulheres freqüentemente aceitam a idéia de que são cidadãs de segunda classe do ponto de vista sexual".

"Quando a mulher abertamente manifesta sua repugnância para com a relação sexual e frigidamente submete-se a ela porque considera uma obrigação conjugal, o marido percebe esta atitude, e na medida em que considera importante a participação da mulher no diálogo sexual, pode sofrer o terror de não ser suficientemente potente para satisfação da mulher e posteriormente pode surgir uma verdadeira impotência. “(Colombino, 1978, p. 167).

Para Munjack (1984. p. 221), a novidade do início do relacionamento contribue para a interação sexual e que com o ocrrer dos anos os casais deixam de explorar alternativas e acham que já fizeram tudo. Sentem-se entediados com a rotina. Alguns utilizam a mesma posição, o mesmo cômodo da casa, o mesmo horário cada vez que mantém relações. Esta falha de variação leva ao tédio e ao decréscimo do desejo sexual.

Kaplan (1983. p. 345), citando mulheres frígidas, diz que esta é a mais severa das inibições femininas. Muitas mulheres não responsivas consideram angustiante a experiência sexual, embora variem na extensão desta aversão a tais experiências. Alguns toleram o contato sexual apenas para manter o casamento; outras, que na verdade repelem o contato sexual, que acham-no assustador e repugnante, vão a grandes extremos para evitá-lo.

Ainda um terceiro grupo de mulheres frígidas, que não experimentam sensações eróticas em resposta à estimulação sexual, é capaz, a despeito disto, de gozar os aspectos físicos não eróticos do contato sexual, tais como as carícias e a intimidade que envolvem o coito. 
"As diferenças do sexo na reação psicológica à disfunção sexual são determinadas ela cultura" (Kaplan, 1977, p. 347). Espera-se que o homem funcione sexualmente e quando tal não acontece, esta disfunção é encarada com patológica. As mulheres não recebem tal pressão e por isso em muitas culturas não espera-se reações sexuais. Ainda hoje em nossa sociedade, a mulher deve proporcionar prazer ao homem e ter filhos.

Quando estas mulheres queixam-se de sua incapacidade de experimentar orgasmo, muitos médicos ainda orientam que a sua falta de resposta é normal e aconselham-nas a aceitá-la a ajustar-se a esta situação.

Kaplan (1977, p. 129) coloca que a história sexual de um número considerável de casais com disfunção revela que eles praticam técnicas sexuais pobres, insensíveis e ineficientes. As técnicas inadequadas são particularmente capazes de prejudicar as respostas das mulheres e homens mais velhos que, quase sempre, requerem uma excitação mais extensiva e mais sensível.

Em alguns casos, os padrões inadequados de fazer amor são apenas resultados de má informação ou ignorância, ao passo que em outros, isso parece ser o produto de sentimentos de culpa e conflitos sexuais, dos quais o casal, geralmente, não tem consciência.

Lima (1976, p. 70) encontrou uma explicação para este tipo de comportamento. Ele acha que o homem que inicia suas relações sexuais com prostituta e acha variações de comportamento clássico papai e mamãe são premíscuos e que para manter a autoridade patriarcal que a sociedade lhe confere, estabelece normas para si e para sua parceira nas relações conjugais.

\section{DISCUSSÃO DOS RESULTADOS}

Conforme os dados encontrados em nossa pesquisa através dos cem (100) pacientes, constata-se que o machismo incide sobre o comportamento sexual de homens e mulheres. Sentindo-se ameaçados pelo fantasma da impotência, muitas vezes de fantasias castrativas, dúvidas, desinformações, os homens buscam auxilio especializado.

Alguns mais machistas ou com maiores dificuldades emocionais fogem de situações em que podem se comprometer ao se verem obrigados a manter relação sexual. Outros utilizam álcool como válvula de escape.

Alguns levam anos para buscar ajuda e só o fazem quando temem perder sua mulher, ou quando outra esteja se insinuando e que não querem desapontar.

Observa-se, na pesquisa, que a idade média equivale a 48 anos, variando dos 17 anos aos 73 anos. Destes, $83 \%$ tem parceira permanente, ganham em média três salários mínimos e possuem na maioria 2 filhos. 
Para Kaplan (1977, p. 249), as dificuldades eréteis podem ocorrer em homens de todas as idades, nos rapazes que estão começando a explorar o mundo da sexualidade, nos homens que estão no auge do vigor sexual, e nos septuagenários, que segundo a autora, podem temer que a idade lhes tenha roubado para sempre a vitalidade.

Dos pesquisadores que disseram ser fácil obter ereção quando a mulher lhes tocava, encontramos $46 \%$ que dependeria da parceira e $39 \%$ se esta participasse da relação. Podendo-se supor que no total $85 \%$ espera da mulher o estímulo para a ereção.

Dos pesquisados, $61 \%$, possuem ereção quando acordam; $30 \%$ obtem ereção durante o dia. Esses dados são importantes uma vez que mostram o quanto o homem dificulta sua ereção com seus pensamentos obssessivos e inseguranças. À noite não foi investigado porque é um dado muito subjetivo.

Acredita-se que para fazer uma investigação desta natureza seria necessário submeter estes pacientes ao Ambulatório do Sono. Três pacientes contaram que eram vigias noturnos o que dificultaria uma investigação também desta hora, pois dormem pouco pela manhã. (Tabela 12 e 13).

Quanto as práticas realizadas no coito, $97 \%$ apreciam beijos e carícias, $89 \%$ gostam de estimulação manual de órgãos sexuais (pênis e clitóris), 93\% preferem a posição superior do homem sobre a mulher. (Tabela 24). Isso nos mostra quão pobres são estas relações sexuais. Sabe-se que a criatividade e fantasia são essenciais para uma boa relação sexual.

Concordamos com Délcio Monteiro de Lima (1976, p. 27), quando coloca que a falta de educação sexual básica, a ignorância e crendices levam os jovens a fracassarem em suas tentativas sexuais. Coloca, ainda, que o conhecimento a respeito da genitália, técnicas que facilitem a excitação sexual e simples informações a respeito de tabus, ajudam no bom desempenho sexual.

Ainda a respeito de pouca informação, em nossa prática diária percebemos que muitos pacientes após os 40 anos desconhecem as modificações fisiológicas decorrentes do processo de envelhecimento orgânico.

Lima (1976, p. 33) explica que a capacidade sexual não tem idade, o que acontece são variações na intensidade e na qualidade das respostas. O homem tem condições de usufruir de uma vida sexual até a morte. O importante é aceitar as modificações fisiológicas do envelhecimento orgânico e procurar tirar o melhor de cada encontro sexual.

Dos que gostam de masturbar-se ao mesmo tempo durante a relação, encontram-se 53\% dos entrevistados, enquanto que $69 \%$ preferem a posição em que a mulher fica por cima e $53 \%$ gostam de fazes sexo de pé. Desses, $54 \%$ alegaram que a relação está tediosa e $61 \%$ sentem-se constrangidos por não se sentirem bons amantes. 
Muitas vezes é a partir deste tipo de sentimento, pelo medo do desempenho, medo de fracassar que se desenvolve um círculo vicioso onde o medo leva ao fracasso, a falta de confiança leva ao fracasso novamente e o homem começa a evitar envolver-se com mulheres, passando mesmo a fugir de qualquer situação mais íntima. A auto estima e a falta de segurança predominam a partir desta situação.

Alguns pacientes relatam que mulheres com roupas eróticas lhes deixam excitados, ter relações em lugares proibidos, arriscados, perigosos onde pudessem ser pegos em flagrante também era excitante. Mas estes tipos de fantasias são bastante raras nesta população. Em geral estes pacientes tem alguma dificuldade muito grande de serem criativos. E predominante o pensamento concreto e a incapacidade de abstrair.

Outros já disseram que preferiam ter relações em motel, de tarde ou de noite, ou pela manhã cedo, em outro local que não habitual, em lugares tranqüilos, escutando música, no quarto e bem escondidinho. Alguns relatam que iniciaram a dificuldade de potência alguns meses após pararem de beber.

Existe a idéia de que não têm mais ereção porque pararam de beber, e que talvez a solução seja voltar a beber. Não se dão conta do motivo que lhes fez começar a beber um dia e suas consequiências. Quanto mais questionados sobre o assunto, acabam concordando que os problemas que tinham antes voltaram novamente ao pararem de beber.

Falando a respeito de alterações na fase do desejo, $47 \%$ alegam que houve uma diminuição em seu desejo, $5 \%$ perderam seu desejo, enquanto que $66 \%$ alegaram terem havido mudanças com relação ao desejo sexual. (tabela 33)

Segundo os pacientes, em relação aos fenômenos psicológicos relacionados com a impotência, (tabela 36) 49\% sentem-se deprimidos, ou porque já eram antes da dificuldade erétil ou em função da dificuldade, $31 \%$ apáticos, $53 \%$ irritados, $55 \%$ ansiosos e $45 \%$ em fadiga, cansados não conseguem fazer nada. Um paciente contou que trabalha tanto que quando chega em casa está muito cansado. Outros, que esta situação esta lhes deixando irritados, ansiosos e deprimidos.

Kaplan (1977, p. 251) diz "que em quase todas as culturas a grupos sócio-econômicos grande parte da auto-estima masculina apóia-se na ereção". Como decorrência disto, a depressão secundária é uma conseqüência comum da impotência.

É importante analisarmos sempre causas e conseqüências quando se fala em depressão e discórdias conjugais, para avaliar o desenvolvimento da origem da depressão $\mathrm{X}$ impotência, discórdias sexuais $\mathrm{X}$ impotência e viceversa.

Entre outros fatores relacionados (tabela 37), 9\% alegam ter medo da velhice, medo que tenham que preocupar-se com eles, $49 \%$ têm problemas de saúde, $26 \%$ possuem problemas com seu trabalho, ocupação ou 
aposentadoria, $36 \%$ problemas financeiros, $23 \%$ problemas familiares, preocupação com os filhos e $36 \%$ problemas relacionados com as parceiras, seja pela dificuldade de relacionamento ou com problemas relacionados com a menopausa.

Muitos falam que as esposas são doentes e, portanto, não têm condições de ter relações com elas, ficando então sem ter relações ou porque tem dificuldades em função da educação, ou por medo de pegar AIDS e outras doenças sexualmente contagiosas.

Alguns pacientes tentam ter relações com outras mulheres por medo de fracassar acabam falhando. Pacientes relatam sentirem-se culpados por procurarem outras mulheres. Esta é uma situação que por si só pode provocar impotência, mesmo que manifestem interesse por elas.

Nas manifestações psicossexuais apresentadas por nossa amostra (tabela 38) 26\% sentiram uma mudança repentina no comportamento sexual; $73 \%$ alegam que a mudança foi gradual; $29 \%$ falaram que não tinham interesse pela parceira; para $10 \%$ o desinteresse era geral; $86 \%$ tinham interesse por outras parceiras; $19 \%$ tem interesse por parceiras mais jovens e somente $1 \%$ disse ter interesse por parceiros do mesmo sexo.

Talvez esse número aumentasse, se o questionário não fosse feito em forma de entrevista, pois na prática diária percebe-se que sobre um assunto como este, o paciente, muitas vezes, só vai falar quando adquire confiança no terapeuta. Somente um paciente falou abertamente sobre sua homossexualidade. Ele era tanto ativo como passivo e estava encontrando dificuldades com o seu atual parceiro.

Nenhum paciente declarou ter interesse por parceiro do sexo masculino mais jovem e tão pouco que apresentava algum desvio de sua sexualidade. Acho que aqui também cabe a colocação feita acima quanto a confiança no terapeuta.

\section{CONCLUSÃO}

A importância de abrir ao máximo um espaço para o paciente clarear a queixa de impotência trazida à consulta é um dos fatores mais importantes nesta pesquisa. Muitas vezes somente com uma ou dias consultas já se resolve a disfunção oriunda de fantasias e desinformações a respeito de seu funcionamento sexual. $\mathrm{O}$ conhecimento de sua genitália, de técnicas para facilitar a excitação sexual e informações a respeito de tabus são responsáveis pela melhora da potência em grande partes dos casos.

Encontramos em nossa amostra o que outras pesquisas já constataram: $86 \%$ de queixas de disfunção erétil secundária, 3\% primária, $9 \%$ ocasional (de vez em quando) e $2 \%$ específica (em determinada situação), 
levando-nos a concluir que em todas as camadas sociais os problemas sexuais são os mesmos e nas mesmas proporções.

A masturbação também é outro tema que não diferencia nas classes sociais, iniciando-se aos 12 anos para a maior parte de nossa amostra a aos 16 anos para o início das relações sexuais.

A homossexualidade pouco encontrada, ou pelo menos declarada por somente $1 \%$ de nossa amostra, é um tema interessante, uma vez que vivemos ainda hoje em uma cultura extremamente machista onde o homem deve corresponder a um "ideal de gaúcho".

Apesar das perguntas variadas, percebemos falhas, tais como aprofundas mais o entendimento dos relacionamentos sexuais anteriores, podendo isto, no entanto, ser assunto de nova pesquisa, ou de aprofundamento desta.

Pensamos que a entrevista com a companheira seria de fundamental importância bem como a participação desta no tratamento, a fim de clarear as dificuldades a respeito da sexualidade humana a mais especificamente da disfunção erétil.

O que se percebeu é que o sexo ainda é visto como tabu. E é de fundamental importância desmitificá-lo. Quem sabe isso poderia ser feito através de informações nas escolhas, em reuniões de bairros e outros locais em que as pessoas de classe baixa pudessem ter acesso.

Percebe-se que o bloqueio sexual pode ser o responsável por um grande número de frustrações, levando as pessoas ao desequilíbrio em suas vidas e comprometendo com isto suas saúde mental. como especialista em saúde mental coletiva, tenho a obrigação de atentar para este tema tão importante e divulgá-lo ao máximo para que tomemos providências o quanto antes tanto a nível primário, secundário como terciário.

A função do terapeuta é verificar se ele tem as ferramentas apropriadas para esse tipo de auxilio e se o processo todo lhe parece ético. No entanto, embora venha crescendo o número de pessoas a casais que buscam dar maior colorido à vida sexual, é ainda a ausência das reações sexuais "exigíveis", como ereção ou dilatação e lubrificação vaginal, o que produz maiores abalos pessoais.

Os frutos que um casal pode recolher da atividade sexual mal-feita ou bem-feita podem ter sabores mais sutis do que o doce do orgasmo. As lutas internas de poder, as culpas pela frustração própria ou do outro, além de toda uma história de vida anterior à relação atual, podem pesar tanto ou mais do que as sensações imediatas. Neste contexto, sexo funciona muitas vezes como sinal de alarme de que algo não vai bem, mesmo quando as aparências superficiais são de absoluta calma e compreensão.

Esse papel de denúncia de uma falsa paz cabe ao sexo, justamente porque ele se fundamenta em reações automáticas, que não podem ser fraudadas com facilidade, nem mesmo pela conveniência de manter uma relação calma. Por outro lado, sexo também é uma arma ponderável, e as 
dificuldades sexuais podem ser usadas como formas de acusação, de vitimização ou até mesmo para compensar relações de dominação-submissão em outras áreas da vida em COMUM.

Nesta pesquisa não se levou em conta o estudo sistemático das relações do casal, pois o próprio conceito do que seja um casal pode se tornar bastante crítico e por certo falta muito ainda para que possa dizer que a dinâmica dessa relação especial entre duas pessoas é um fato cientificamente estudado.

Para o propósito da pesquisa sobre a disfunção erétil do homem de classe baixa, e sua compreensão creio que forum dados passos importantes, pois a pesquisa revela que não ocorrem diferenças significativas com outras já realizadas em camadas sociais mais elevadas. Dizemos então que a queixa de disfunção erétil ocorre em todas as camadas sociais e que os problemas apresentados são os mesmos, ou seja, não diferem significativamente.

Podemos ainda supor que o fator idade possa estar relacionado com a disfunção, pelo fato dos pacientes estarem na sua maioria na faixa da meia idade. "Pois nesta meia-idade, os homens "descobrem", subitamente, que o mito da masculinidade é potência, e potência é poder. E estes se mantêm muitas vezes graças a máscara que oculta sentimentos, tensões e apreensões existentes.

Percebe-se que é muito importante esmiuçar ao máximo as queixas trazidas pelo paciente para compreender o que ele está tentando dizer. Muitas vexes é ignorância ao próprio aparelho sexual e seu funcionamento, fantasias e idealizações que o levam a pensar que ele é diferente ao comparar-se com outros homens, pelo que vê em filmes pornográficos, ou lê em revistinha eróticas ou mesmo escutando outros homens contarem vantagem.

O conceito de disfunção assemelha-se a uma espécie de "insatisfação de desempenho", referindo-se aos casos em que o encontro sexual termina com algum nível de frustração.

Nas relações de longa duração, onde a falta de tempo, as desavenças, as muitas rotinas a mesmo a delimitação de espaço físico tornaram a prática sexual empobrecida, não se classificariam de disfunção. Todas as fases acontecem, talvez sem brilho, mas acontecem.

É preciso que os dois parceiros reconheçam o tédio que se insinua; seria bom de se ouvir os pensamentos mais profundos que ambos esconderam durante muito tempo, e que agora teriam um papel restaurador. A experiência também tem sua importância. E talvez só com a idade, quando a personalidade alcança seus últimos estágios de desenvolvimento, o sexo tem a possibilidade de se tornar maior do que em qualquer outra época da vida. Pode ser alegre e criativo, saudável e criador de saúde. 


\section{REFERÊNCIAS BIBLIOGRÁFICAS}

1. BEE, Helen: A Criança em Desenvolvimento. $3^{\circ}$ ed., Sao Paulo, 1984.

2. COLOMBINO, Andres Flore. Patologia y Clínica de la Impotência Sexual. Buenos Aires: Hormé (Paidós), 1978,

3. FUCS, Gilda Bacal. Manual Feminino: Masculino de Investigação Sexual. São Paulo: Nobel, 1985.

4. FOGEL, Lane et elli: Psicologia Masculina: Novas Perspectivas Psicanalíticas. Porto Alegre: Artes Médicas, 1989.

5. GILLAN, Richard: A Terapia Sexual. $7^{\circ}$ ed., Lisboa, 1988.

6. KAPLAN, Helen Singer: A Nova Terapia do Sexo, $5^{\circ}$ ed. Rio de Janeiro: Nova Fronteira, 1977.

7. _ O Desejo Sexual. Rio de Janeiro: Nova Fronteira, 1983.

8. KUSNERTZOFF, Juan Carlos: O Homem Sexualmente Feliz. $2^{\circ}$ ed. Rio de Janeiro: Nova Fronteira, 1987.

9. LIMA, Délcio Monteiro de.: Comportamento Sexual do Brasileiro. Rio de Janeiro, 1976.

10.

: Manual de Medicina Sexual. São Paulo: Manole, 1982.

11. MASTERS, Willian H. \& Johnsn, Virginia E.: A Resposta Sexual Humana. São Paulo, 1984.

12. : A Inadequação Sexual Humana. São Paulo: Roca, 1985.

13. _ : O Relacionamento Amoroso: Segredos de Amor e da Intimidade Sexual. Rio de Janeiro: Nova Fronteira, 1988.

14. MITCHELL, Sandra K. \& Bee, Helen: A Pessoa em Desenvolvimento. Rio de Janeiro, 1984.

15. MUNJACK, Dennis: Sexologia, Diagnóstico e Tratamento. Rio de Janeiro: Atheneu, 1984.

16. HUSSEN, Conger e Kagan: Desenvolvimento e Personalidade da Criança. São Paulo: Harba. $4^{\circ}$ ed., 1977.

17. SAPETTI, Adrian e Kaplan: Mário y La Sexualidad Masculina. Buenos Aires: Galerna, 1986.

18. SILVA, Chalar Araguari: Terapia do Sexo e Dinâmica do Casal. Rio de Janeiro: Espaço e Tempo. 1989.

19. SUPLICY, Marta: Conversando Sobre o Sexo. Rio de Janeiro: Petrópolis. Vozes $15^{\circ}$ ed., 1987.

20. WINCZE, John P. and Corey, Micchel P.: Sexual Disfunction: A guide for assesment and treatment. New York, Guil-For Press, 1991. 


\section{Número de Pessoas Entrevistadas: 100}

\begin{tabular}{|c|c|c|c|}
\hline \multicolumn{4}{|c|}{ 1 - Idade } \\
\hline & Minıma: & 17 & \\
\hline & Média: & 48 & \\
\hline & Múxima: & 73 & \\
\hline $2-$ & Cor & & \\
\hline & Outras: & 6 & \\
\hline & Negra: & 13 & \\
\hline & Branca: & 81 & \\
\hline $3-$ & Religião & & \\
\hline & Assembléia de & Deus: & $1 \%$ \\
\hline & Protestante: & & $1 \%$ \\
\hline & Episcopal: & & $1 \%$ \\
\hline & Mormon: & & $1 \%$ \\
\hline & Luterana: & & $2 \%$ \\
\hline & Judaica: & & $2 \%$ \\
\hline & Ateus: & & $3 \%$ \\
\hline & Umbanda: & & $4 \%$ \\
\hline & Espirita: & & $5 \%$ \\
\hline & Evangélica: & & $9 \%$ \\
\hline & Católica: & & $69 \%$ \\
\hline 4. & Estado civil & & \\
\hline & Viúvo: & $2 \%$ & \\
\hline & Separado: & $3 \%$ & \\
\hline & Desquitado: & $7 \%$ & \\
\hline & Solteiro: & $15 \%$ & \\
\hline & Casado: & $73 \%$ & \\
\hline
\end{tabular}

5 - Renda individual

$\begin{array}{ll}\text { Mínima: } & 1 \text { salário mínimo } \\ \text { Médio: } & 2 \text { salários mínimos } \\ \text { Máxima: } & 3 \text { salários mínimos }\end{array}$

6 - Renda do casal

$\begin{array}{ll}\text { Mínima: } & 1 \text { salário múnimo } \\ \text { Média: } & 2 \text { salários mínimos } \\ \text { Máxima: } & 3 \text { salários mínimos }\end{array}$

7 - Parceira permanente
Não:
$17 \%$
Sim:
$83 \%$

8- Número de filhos

$\begin{array}{ll}\text { Mínima: } & 0 \\ \text { Média: } & 2 \\ \text { Máxima: } & 9\end{array}$

9 - Disfunção erétil

Especiffica: $\quad 2 \%$

Primária: $\quad 3 \%$

Ocasional: $\quad 9 \%$

Secundaria: $86 \%$

10 - Perda de interesse sexual

Sim: $\quad 37 \%$

Não: $\quad 61 \%$

11 - Utiliza masturbação

Sim: $\quad 35 \%$

Não: $\quad 65 \%$

12 - Ereção matinal

Sim: $\quad 61 \%$

Nito: $\quad 39 \%$

13 - Ereçăo diurna

Sim: $\quad 30 \%$

Não: $\quad 70 \%$

14 - Parceira coopera, é amorosa

Brancos: $\quad 14 \%$

Sim: $\quad 45 \%$

Não: $\quad 41 \%$

15 - Parceira gosta de sexo, sente prazer

Brancos $14 \%$

Sim $\quad 46 \%$

Nĩo $\quad 40 \%$

16 - Início da atividade sexual

$\begin{array}{lr}\text { Mínima } & 7 \% \\ \text { Média } & 16 \% \\ \text { Míxima } & 52 \%\end{array}$

17 - Com quem teve início a atividade sexual Eguas e bichos $1 \%$

Prima $1 \%$

Menino $2 \%$

Esposa $3 \%$

Empregada $6 \%$

Vizinha $\quad 65 \%$

Conhecida $\quad 8 \%$

Namorada $\quad 8 \%$

Amiga $\quad 18 \%$

Prostitutal $\quad 47 \%$ 
18 - Início da atividade sexual teve sucesso Sim $\quad 94 \%$

Não $6 \%$

19 - Primeỉra masturbação

Mínima $8 \%$

Médial $\quad 12 \%$

Máxima $\quad 17 \%$

\section{0 - Experiências heterossexuais}

$\mathrm{Sim} \quad 99 \%$

Não $\quad 1 \%$

21 - Experiências homossexuais

Sim $24 \%$

Não $\quad 76 \%$

22. Desejo de copular

Variáve

Quinzenal

Semanal

Dias alternados

Raro

Varias vezes ao dia $5 \%$

2 vezes por semuni $14 \%$

3 vezes por semana $19 \%$

Todos os dias $39 \%$

23 - Freqüência de coito

Várias vezes por semanat $0 \%$

Dias alternados $\quad 1 \%$

Todos as dias $\quad 5 \%$

3 vezes por semana $6 \%$

variável $7 \%$

2 vezes por semana $14 \%$

24 - Práticas do coito

Falta de privacidade doméstica para

atividade sexual

Utilização de objetos

Preferência por relações homossexuajs

Uso de lubrificantes superficiais

Preferencia por determinadas situaçōes

Discordância sobre os tipos de

atividades sexuais

Preferência por determinadas ocasiòes

Violência untes. durante elou após o coito

Posição de lado

Fantasias eróticas especificas

Constrangimento por sentir que seu

corpo não é sensual
Preferĉncia por determinados horários

$24 \%$

Fata de cempo para relaxar e desfrutar

do sexo

Discordancia sobre a quen catbe it

iniciatival

Coito and

Desprazer con a natureza do sexo $29 \%$

Discordância sobre frequientes recusas às investidas do parcciro

Estrmulaçĭo oral

Discordânciat sobre qual o momento

da relução

Preferência por determinadas posições

Discorduncia sobre a frequiência da

relaçĩo

Posiçấo sentindil

Preferência por deteminados locais

Faltil de conhecimento ou habilidade

sexual

Faltil de conhecimento da téenica/

habilidade para excitar-se mutuamente $49 \%$

Masturbação simultâna $\quad 53 \%$

Posiç̄o de pé $\quad 53 \%$

Tédio en relaçäo ato sexo $\quad 54 \%$

Constrangimento por não se sentir bom

amante

$61 \%$

Mulher em posição superior

$69 \%$

Estimulação manual - pênis e clitóris $\quad 89 \%$

Prefcrência por uma relaçăo hetero $\quad 94 \%$

Homem em posiço superior $\quad 93 \%$

Bcijos e caricias

$97 \%$

\section{5 - Obtenção das ereções}

Apenas creçäo matinal

Não consegue con deteminado parceiro 08

Fácil a estimulação olfativă $\quad 13$

Dificil com determinada parceira , 11

Fácil a estimulação aluditiva $\quad 19$

Difícil especítico a uma parceira 20

Fúcil mediante fantasias eróticas

específicits

Nunca consegue com parceira $\quad 25$

Fácil à estimulação visual $\quad 28$

Jamais consegue $\quad 30$

Năo consegue com parceira

específical

Difícil com qualquer parceira $\quad 36$

Fácil a depender da parceira $\quad 39$

Fácil a estimulação tátỉ] $\quad 46$ 


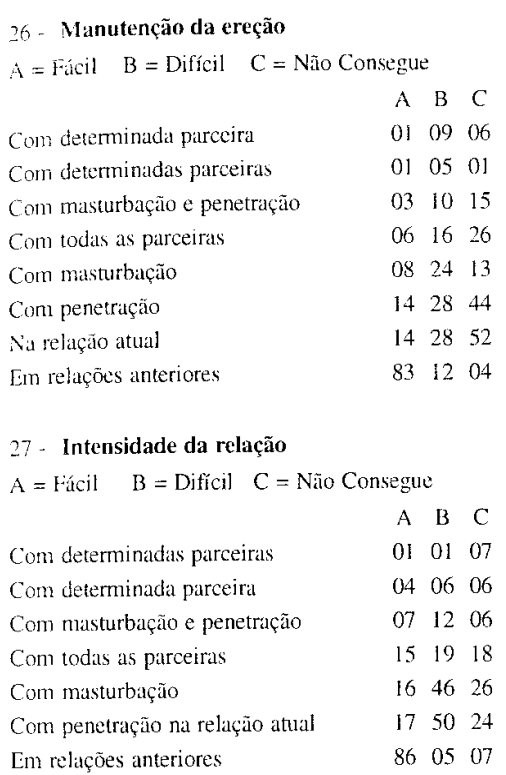

\section{8 - Obtenção do orgasmo}

$\mathrm{A}=$ Fácil $\mathrm{B}=$ Difícil $\mathrm{C}=$ Não Consegue

Com detcrminadas parceiras

$\wedge \mathrm{B} \quad \mathrm{C}$

Com determinada parceira

$04 \quad 0201$

Com penetraçĩo

Com todas as parceiras

Com masturbação

Com masturbação e penetração

090601

$\begin{array}{lll}24 & 05 & 02\end{array}$

31 $12 \quad 02$

$\begin{array}{lll}37 & 07 & 00\end{array}$

$\begin{array}{lll}37 & 20 & 07\end{array}$

Conn penetraçao

Nà relaçĩo atual

Em relação anteriores

$\begin{array}{lll}61 & 20 & 07\end{array}$

$61 \quad 21 \quad 10$

930601

29 - Tempo de obtenção de orgasmo

$\mathrm{L}=$ Longo $\mathrm{S}=$ Suficiente $\mathrm{I}=$ Insuficiente

$\mathrm{P}=$ Pouco Tempo

Con determinada parceira

Com masturbação e penetração

Conı masturbação

$\begin{array}{llll}\mathrm{L} & \mathrm{S} & \mathrm{I} & \mathrm{P}\end{array}$

Com determinada parceira

Com todis as parceiras

Em reluçôes anteriores

$\begin{array}{llll}00 & 02 & 03 & 06\end{array}$

$\begin{array}{llll}01 & 12 & 07 & 11\end{array}$

$\begin{array}{llll}03 \quad 20 & 13 & 11\end{array}$

$\begin{array}{llll}03 & 07 & 02 & 04\end{array}$

$\begin{array}{llll}06 & 13 & 11 & 16\end{array}$

$\begin{array}{llll}09 & 55 & 17 & 19\end{array}$

Com penetraçĩo

$\begin{array}{llll}11 & 24 & 27 & 28\end{array}$

Na relação atual

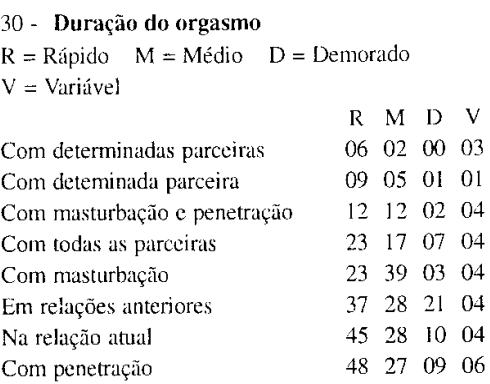

31 - Intensidade do orgasmo

Com determinadas parceiras

A B C

$\begin{array}{lll}02 & 03 & 03\end{array}$

$\begin{array}{lll}05 & 05 & 05\end{array}$

$\begin{array}{lll}15 & 07 & 08\end{array}$

$\begin{array}{lll}23 & 09 & 13\end{array}$

$\begin{array}{lll}24 & 08 & 14\end{array}$

41 $22 \quad 27$

$\begin{array}{lll}41 \quad 22 & 24\end{array}$

$8206 \quad 10$

\section{2 - Quantidade do orgasmo}

$\mathrm{U}=$ Único $\mathrm{MU}=$ Mais de um $\mathrm{M}=$ Múltiplos $\mathrm{P}=$ Prolongado $\mathrm{NT}=\mathrm{Não}$ tem

\section{Com determinadas parceiras}

Com determinada parccira

$\mathrm{U}$ MU $M \quad \mathrm{P} N \mathrm{NT}$

$\begin{array}{lllll}03 & 05 & 00 & 03 & 00\end{array}$

Com masturbação e penetração $\begin{array}{llllll}24 & 04 & 00 & 02 & 02\end{array}$

Em relações anteriores $\quad 30 \quad 3604 \quad 00 \quad 00$

Com todas as parceiras $\quad 3211000201$

$\begin{array}{lllllll}\text { Com masturbação } & 38 & 08 & 01 & 01 & 01\end{array}$

Na relaçĩo attual $\quad 67 \quad 13 \quad 00 \quad 01 \quad 10$

Compenetração $\quad 72 \quad 1400000$ !

33 - Alterações na fase do desejo

Sim Não

Perda $\quad 05 \quad 92$

Inalteração $\quad 33 \quad 66$

Diminuição $\quad 47 \quad 51$

$\begin{array}{lll}\text { Aumento } & 82 & 17\end{array}$

34 - Alterações na fase da excitação

Sim Não

Perda da ereção peniana completa $\quad 09 \quad 90$

Retardamento da ereção peniana
completa

Aumento dil periodo refratório $\quad 32 \quad 67$

Rckardamento da ereção peniana $\quad 44 \quad 55$

Incapacidade de mantenção da ereção $85 \quad 15$ 


\begin{tabular}{|c|c|c|c|c|c|}
\hline \multicolumn{3}{|l|}{ 35- Alteraçôes na fase orgásmica } & \multicolumn{3}{|l|}{ 38- Manifestações psicossexuais } \\
\hline & $\operatorname{Sim}$ & Não & & $\operatorname{Sim}$ & Não \\
\hline \multirow{2}{*}{$\begin{array}{l}\text { Retardamento do controle } \\
\text { ejaculatónio }\end{array}$} & & & Interesse por parceiros mais jovens & 00 & 98 \\
\hline & 19 & 82 & Interesse por parceiro do mesmo sexo & 01 & 98 \\
\hline \multirow{3}{*}{$\begin{array}{l}\text { Diminuição do controle ejaculatório } \\
\text { Diminuiçâo da quantidade do } \\
\text { ejaculado }\end{array}$} & 33 & 65 & Desinteresse geral & 12 & 87 \\
\hline & & & Interesse por parceiras mais jovens & 19 & 81 \\
\hline & 36 & 62 & Desinteresse pela parceira & 28 & 63 \\
\hline \multirow{3}{*}{$\begin{array}{l}\text { Perda de controle ejaculatónio } \\
\text { Que forçam a expulsão de líquido } \\
\text { seminal }\end{array}$} & 40 & 60 & Mudança repentina no comportamento & & \\
\hline & & & sexual & 26 & 74 \\
\hline & 44 & 53 & Mudança gradual no comportamento & & \\
\hline \multirow{2}{*}{$\begin{array}{l}\text { Diminuição da frequência da contração } \\
\text { do mercado }\end{array}$} & & & sexual & 72 & 27 \\
\hline & 47 & 50 & Interesse por outras parceiras & 84 & 12 \\
\hline $\begin{array}{l}\text { Diminuição da intensidade das } \\
\text { construçôes }\end{array}$ & 45 & 52 & \multicolumn{3}{|l|}{$\begin{array}{l}39 \text { - Manifestações hipotalâmicas e/ou } \\
\text { cardivasculares "neurovegetativas" }\end{array}$} \\
\hline \multicolumn{3}{|c|}{36 - Fenômenos psicológicos relacionados } & & Sim & Não \\
\hline & $\operatorname{Sim}$ & Não & Sudorese noturna & 19 & 80 \\
\hline Apatia & 32 & 67 & Espasmas musculares & 22 & 76 \\
\hline Excitabilidade & 45 & 52 & Sudorese acentuada & 21 & 77 \\
\hline Fadiga & 46 & 53 & Palpitações & 24 & 75 \\
\hline Depressĩo & 48 & 51 & & & \\
\hline Irritabilidade & 55 & 44 & 40 - Manifestações metabólicas & & \\
\hline Ansiedade & 54 & 45 & & $\operatorname{Sim}$ & Não \\
\hline 37 - Fatores relacionados & & & $\begin{array}{l}\text { Aumento da taxa de } 1 . I l \\
\text { Aumento das taxas de colesterol }\end{array}$ & 04 & 64 \\
\hline & $\operatorname{Sim}$ & Nĭo & Aumento da taxa de FSH & 06 & 60 \\
\hline Medo da velhice & 10 & 88 & Aumento das taxas de trigliceridios & 14 & 55 \\
\hline Problemas familiares & 23 & 75 & Diminuição das taxas de testosterona & 15 & 50 \\
\hline $\begin{array}{l}\text { Problemas com ocupação } \\
\text { (aposentadoria) }\end{array}$ & 25 & & & & \\
\hline Problemas financeiros & $\begin{array}{l}25 \\
36\end{array}$ & $\begin{array}{l}14 \\
63\end{array}$ & 41 - Uso de medicaçoes & Sim & Não \\
\hline Problemas relacionados a parceira & 36 & 53 & Androgêneos & 4 & 55 \\
\hline Problemas com saúde & 47 & 51 & Outros & 31 & 62 \\
\hline
\end{tabular}

